\title{
The science and politics of human well-being: a case study in cocreating indicators for Puget Sound restoration
}

\author{
$\underline{\text { Kelly Biedenweg }}^{1}$, Haley Harguth $^{2}{ }^{\text {and } \text { Kari Stiles }^{3}}$
}

\begin{abstract}
Across scientific fields, there have been calls to improve the integration of scientific knowledge in policy making. Particularly since the publication of the Millennium Ecosystem Assessment, these calls increasingly refer to data on human well-being related to the natural environment. However, policy decisions involve selective uptake of information across communities with different preferences and decision-making processes. Additionally, researchers face the fact that there are important trade-offs in producing knowledge that is simultaneously credible, legitimate, socially relevant, and socially just. We present a study that developed human well-being indicators for Washington State's Puget Sound ecosystem recovery agency over 3 years. Stakeholders, decision makers, and social scientists were engaged in the identification, modification, and prioritization of well-being indicators that were adopted by the agency for tracking progress toward ecosystem recovery and strategic planning. After substantial literature review, interviews, workshops, and indicator ranking exercises, 15 indicators were broadly accepted and important to all audiences. Although the scientists, decision makers, and stakeholders used different criteria to identify and prioritize indicators, they all agreed that indicators associated with each of 6 broad domains (social, cultural, psychological, physical, economic, and governance) were critical to assess the holistic concept of well-being related to ecosystem restoration. Decision makers preferred indicators that mirrored stakeholder preferences, whereas social scientists preferred only a subset. The Puget Sound indicator development process provides an example for identifying, selecting, and monitoring diverse concepts of well-being related to environmental restoration in a way that promotes recognition, participation, and a fair distribution of environmental benefits across the region.
\end{abstract}

Key Words: decision-making criteria; indicators; integrating science and policy; justice

\section{INTRODUCTION}

The most persistent observation in the literature on utilization [of science] is that researchers and users belong to separate communities with very different values and ideologies and that these differences impede utilization. (Beyer and Trice 1982:608)

The well-being of human communities is inextricably linked to the health of the earth's biophysical environment (Yee et al. 2012, Biedenweg et al. 2016). Humans rely on nature for physical, economic, and cultural benefits (Daily 1997), while ecosystems across the globe are influenced by human actions (Collins et al. 2011). This acknowledgement is the foundation of the term "social-ecological systems" (Ostrom 2009). The key to managing for healthy social-ecological systems is to effectively integrate environmental, economic, and societal needs, combining the specificity of science with the holistic nature of community decision making (Yee et al. 2012).

Scientific data is widely recognized as a critical component for monitoring and predicting future trends of ecosystem health and developing appropriate management strategies (Yee et al. 2012). However, although ecological indicators have been well established for many regions (e.g., National Research Council 2000), social indicators specific to conservation have been under debate. Within the past decade, studies have explored the dimensions of human well-being influenced by the management of the natural environment for diverse stakeholder groups (e.g., Donatuto et al. 2011, Scott 2012, Biedenweg et al. 2014, Amberson et al. 2016). Although there seems to be general agreement in the broad categories of well-being that are relevant, e.g., economic, social, cultural, and psychological, the measurable indicators for those categories appear to be context specific
(Biedenweg 2017). To ensure that management decisions are taking into consideration aspects of well-being that are most closely tied to the health of the ecosystem or influenced by management actions, most resource management agencies will need to complete a process for selecting human well-being indicators relevant to their specific social-ecological system issues.

The process and criteria by which indicators are selected, as with most planning processes, are subject to bias that could affect certain stakeholder groups inequitably (Norton 2015). For example, the primary social metrics used historically have been economic indicators (Diener and Suh 1997) such as natural resource jobs and GDP. Although these metrics represent the values of many people, they do not represent those whose values and well-being are dependent on noneconomic benefits, such as aesthetic opportunities and cultural practices in natural environments (Satterfield et al. 2013). Public institutions and organizations that receive funding from public institutions, covering many natural resource and conservation groups, are accountable to all their constituents and, by definition, should be concerned with the equitable distribution of benefits throughout the policy process. Moreover, not only does this attention to social justice fulfill a moral obligation, but consideration of diverse perspectives and interests can also result in greater management success (Ban et al. 2013).

Integrating well-being science and policy for social justice Across scientific fields, there have been calls to improve the integration of scientific knowledge into policy making, including the use of "best available science" when making decisions (Sullivan et al. 2006, Rudd 2011, Sutherland 2011, Jenkins 2012, Young et al. 2014). The standard practice for integrating scientific 
knowledge into policy tends to be linear, maintaining a gap between the information creator and the information user (Young et al. 2014). This approach is flawed, however, in that it ignores the fact that knowledge is often more relevant when cocreated (Cash et al. 2006), that the policy process incorporates a variety of information types and competing values (Rose 2015), and that scientific information often does not match policy needs and timelines (Vogel et al. 2007). These flaws have resulted in recommendations to engage in interdisciplinary, two-way interaction focused on building interpersonal relationships to address scientific and policy needs (Young et al. 2014). In particular, researchers have suggested that scientists and decision makers conduct more "boundary work" (Rose 2015), jointly developing research and policy, promoting transdisciplinary research, incentivizing long-term dialogue among decision makers and scientists, and embedding scientists in policy-making agencies (Jenkins et al. 2012, Young et al. 2014, Rose 2015).

The lack of utilization of scientific data is a pervasive issue, to the extent that researchers in the field of management try to understand this great divide (i.e., Pelz 1978, Beyer and Trice 1982). They have found that policy decisions involve iterative, selective uptake of information across inherently different communities with different values and processes, whereas scientific information is based on a structured, data-gathering process by a select group of individuals. The integration of these various methods and preferences implies important trade-offs to produce "knowledge that is simultaneously credible, legitimate and relevant" (Young et al. 2014:389). We argue that this is also critical for producing knowledge that can result in socially just decisions.

The consideration of social justice in environmental issues has diverse theoretical foundations (Schlosberg 2007, Edwards et al. 2016). Early theories in the United States focused on distributing risks equitably across social groups that often received disproportionate impacts based on their social class or race (Schlosberg 2013, Martin et al. 2016). More recently, environmental justice frameworks have become increasingly pluralistic, as represented in Amartya Sen's (1999) foundational work on capabilities. This conceptualization argues that justice goes beyond the distribution of risks and benefits to incorporate recognition and participation in a process (Edwards et al. 2016). In so doing, it prioritizes the ability of individuals to live the life that they personally define as worthwhile.

Although rarely explicit in the justice literature, some argue that the capabilities approach to environmental justice is inherently about guaranteeing individual and community well-being (Edwards et al. 2016). The theoretical foundations of well-being can be found in several social sciences. Within economics and development, Sen (1999) identified subjective satisfaction, material support, and the ability to fulfill an autonomous life as three critical components of well-being. The psychological literature identifies two fields of well-being: hedonic, the experiences that influence an individual's daily happiness; and eudaimonic, the broad components that allow the community to "live the good life" (Kahneman et al. 2003). The hedonic conceptualization of well-being may be more aligned with the traditional equity-based approaches to environmental justice, whereas eudaimonic well-being may be better framed by pluralistic constructs of environmental justice (Edwards et al.
2016). Anthropology, geography, and sociology may consider well-being in a more relational sense (White 2010), where wellbeing is a process rather than a state. In this case, measurement of well-being would be more qualitative and grounded in political processes rather than quantitatively grounded in science.

Because of the fundamental link between well-being and social justice, selecting human well-being indicators to inform conservation strategies provides many opportunities to promote justice. For example, scientists tend to rate potential indicators based on various dimensions of their scientific rigor (Samhouri et al. 2009), decision makers may be more concerned with whether the potential indicators are understandable to the broad public, and members of the public may be motivated by the factors that will enable their individual daily happiness. One way to make these preferences transparent is by using criteria to guide decision making (Samhouri et al. 2009). Criteria are explicit qualities that represent the values of those making a choice, such as whether the indicator is theoretically sound or easily understood.

We compare the preferences for human well-being indicators by local stakeholders, social scientists, and regional decision makers. We will answer the following questions using a case study based in the Puget Sound of Washington State: How can the integration of stakeholder, scientific, and policy preferences help us integrate local, scientific, and political priorities when selecting indicators of well-being that will be used for natural resource monitoring and target setting? What does the selection of well-being indicators have to do with social justice?

\section{Context}

The Puget Sound is home to more than 4 million people living in 12 counties and 19 tribes, spread across 4 marine basins (Puget Sound Institute 2015). This complex social-ecological system has a state governing body, the Puget Sound Partnership (the Partnership), that is charged with coordinating the recovery of Puget Sound from mountain tops to white caps with 6 main goals (Puget Sound Partnership 2014):

1. Healthy people are supported by a healthy Puget Sound.

2. Our quality of life is sustained by a healthy Puget Sound.

3. Species and the web of life thrive.

4. Habitat is protected and restored.

5. Rivers and streams flow at levels that support people, fish, and wildlife.

6. Marine and fresh waters are clean.

The Partnership has three governing and advisory bodies: the Science Panel (SP), an interdisciplinary group of 13 regional experts that act as scientific advisers; the Ecosystem Coordination Board (ECB), a group of 27 diverse stakeholder representatives from federal, state, local, and tribal governments, natural resource industries, business and development, and environmental nongovernmental organizations (NGOs) that act as stakeholder advisers; and the Leadership Council (LC), which is a governorappointed council of 7 citizens tasked with making executive decisions. Partnership coordination involves cities, counties, tribes, private companies, state and federal agencies, and academic and nonprofit organizations. Henceforth, the term "decision makers" will apply to both the ECB and the LC. 
In 2010, the Partnership adopted 21 "vital signs," or scienceinformed measures made up of 1 or more indicators and associated recovery targets, to monitor the status of recovery and facilitate strategy development. These initial indicators were largely focused on the ecological system, goals 3 through 6 in the statute, with the charge of developing appropriate human health and well-being indicators over time (Wellman et al. 2014). For example, water quality indicators included metrics of toxics in fish, marine sediment quality, freshwater quality, and marine water quality; the water quantity indicator is summer stream flows; habitat indicators include estuaries, floodplains, land development and land cover change, eelgrass (Zostera marina) beds, and shoreline armoring; and species and food web indicators include birds, Pacific herring (Clupea pallasii), orcas (Orcinus orca), and Chinook salmon (Oncorhynchus tshawytscha). We describe the process and lessons learned from developing human health and well-being indicators that were theoretically robust, practically relevant, and socially just. We 3 authors formed the core team that designed and implemented the project over 3 years.

\section{A conceptual model}

The Partnership's task of leading and coordinating the recovery of Puget Sound requires a strong foundation of science-based theoretical application and a nuanced understanding of the Puget Sound social-ecological system, integrating across biophysical and social components to achieve ecosystem outcomes related to the six goals (Harguth et al. 2015). As with most natural resource management agencies, development of an ecological framework, including metrics for ecological health across different scales, organisms, and ecosystems, received early attention. The social framework followed a few years later, yet specific metrics had not been developed as of 2015. Additionally, the connections between these two frameworks, the social-ecological system, were nebulous. Thus, prior to developing social indicators to highlight priority science and management actions, the project team consulted biophysical and social scientists, as well as agency staff and decision makers, to develop a social-ecological system conceptual model specific to the Puget Sound (Fig. 1).

Fig. 1. Integrated conceptual model of Puget Sound restoration adopted by the Puget Sound Partnership.

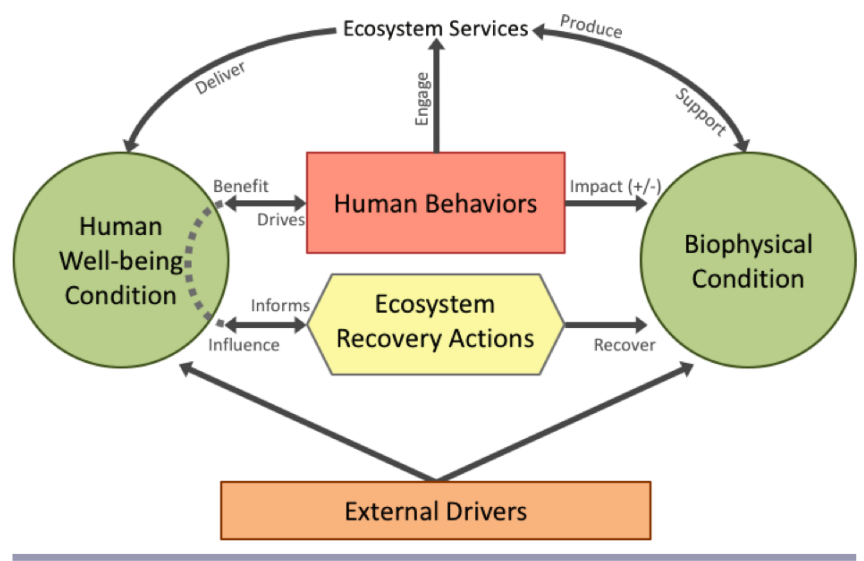

The integrated model distinguished the two types of goals for Puget Sound recovery, those related to human well-being and those related to biophysical condition, and articulated how other components of the ecosystem could affect achievement of those goals. The primary intention of the model was to demonstrate the recursive nature of human well-being. Rather than frame it as merely an outcome of the biological condition, as is represented in the Millennium Ecosystem Assessment (2005), we positioned it as both a determinant of human behaviors that positively and negatively affect the biological environment as well as dependent on the benefits and limits associated with ecosystem services and natural resource management strategies. We believed that this was a true representation of the feedback loops within a socialecological system, and thus a critical step to ensure we were monitoring the key components of the system. Unintentionally, in presenting well-being as a capability that shapes behaviors, the model also acknowledges that without well-being we cannot have a socially just social-ecological system.

To qualitatively analyze the ability of the Partnership to monitor the full social-ecological system with its existing 21 vital signs, the research team added colored wedges representing each vital sign to the location on the conceptual model that they would monitor (Fig. 2). The vital signs were placed on a shape if they were a direct measure of that construct and on an arrow if they were more a proxy that was predictive of the construct. In doing this exercise, we highlighted what we already suspected: human wellbeing condition was poorly addressed by the original vital signs that were adopted based on the best available ecological science and the political interests of the time. A number of the vital signs indirectly measure human well-being, but there were no direct measures of human well-being; quality of life was proposed but never developed.

Fig. 2. Integrated conceptual model with "wedges" demonstrating the initial vital signs prior to the study. PSP, Puget Sound Partnership.

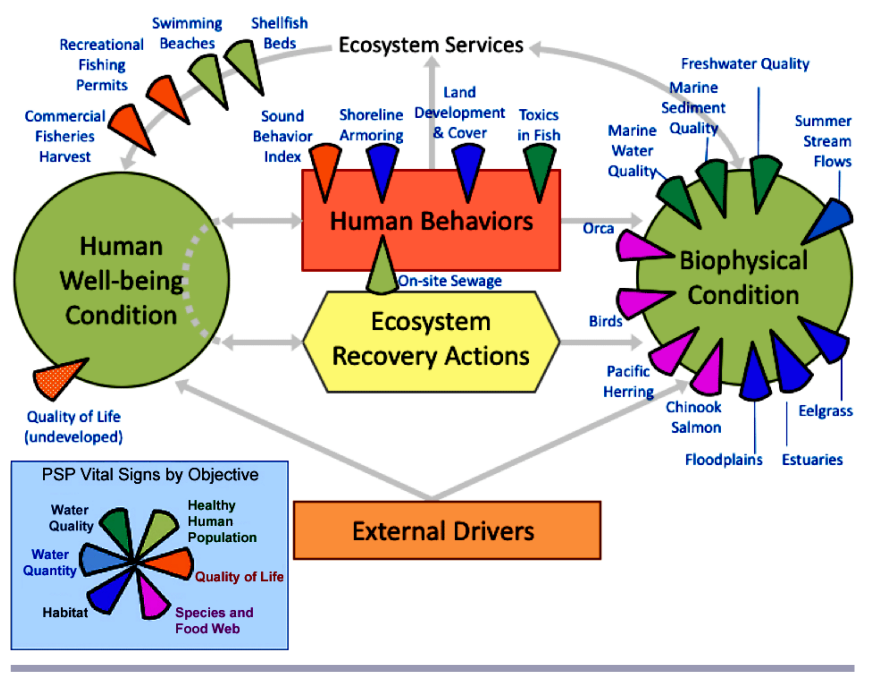

\section{METHODS}

Indicator development and rating

The process for developing and adopting indicators occurred in three stages. First, the research team worked with residents from three local watersheds to identify locally relevant human wellbeing indicators and test the hypothesis that there was too much 
Table 1. Criteria used for ranking human well-being indicators by different groups.

Community Stakeholders

Decision Makers

Relevance to local human well-being

Relevance to regional human well-being

Importance for comprehensively representing human well-being Importance for comprehensively representing human well-being Relevant to management concerns

Understandable by public and policy makers

Linkable to measurable reference points and targets

Social Scientists

Pertinent to state and condition of regional human well-being

Theoretically sound

Responsive and sensitive to changes

Operationally simple

Cost-effective

High signal-to-noise ratio

Consistently measurable

Demographic, temporal, spatial variation understood and detectable

Relevant to management concerns

Responsive and sensitive to management actions

Understandable by public and policy makers

Linkable to measurable reference points and targets

variability to find common human well-being indicators across different settings (Biedenweg 2017). The local areas differed in social-ecological context; one had an urban center, another was an agricultural breadbasket, and the third was relatively pristine with second-home owners and generations-old resource-based communities. In each region, indicators were developed using interviews, literature review, and stakeholder workshops. Our approach to defining these indicators was focused on the psychological construct of hedonic well-being. Specifically, we asked people to consider how their natural environment contributed to their well-being, which primed participants to think about their individual states of happiness. Using a snowball sampling approach that asked interviewees to recommend someone who had very different preferences from them, we sought to balance the representation of different social groups in the conceptualizing of indicators.

Stakeholders were invited to participate in workshops based on their specialized knowledge about each of the human well-being domains that prevailed from the interviews; for example, employees from environmental and community public health departments, as well as recreation-based NGOs, provided feedback on the physical and psychological health domains; members of chambers of commerce, agriculture extension, conservation districts, and natural resource-based industries rated indicators in the economic domain; and leaders from churches and community-based organizations contributed to the social and cultural domains. Tribal members were invited to participate in all groups. Although we acknowledged that each of these individuals also held knowledge beyond their assigned domains, because of cognitive limitations we justified that each participant would only be able to focus on one group in the available time. Moreover, participants were invited to participate in whichever group they preferred, although most chose to work in a group for which they believed they held the most knowledge of data-driven evidence or broad experience. Participating stakeholders were asked to rate proposed indicators based on their relevance and importance (Table 1). We defined relevant as "meaningful to stakeholders and representative of management priorities" and important as "providing unique added value to the existing list of indicators, rather than being redundant." The resulting indicators from the three regions were then compared for similarity. Twenty-three indicators were highly rated by stakeholders according to these criteria in at least two regions (Table 2).

Although the primary goal of the workshops was to ensure diverse representation of indicators, it was at this point that we identified the impracticality of developing a legitimate interaction for all stakeholders. For example, several rural Tea Party members refused to participate because they felt threatened by the structure of the meeting. Specifically, they disliked having four facilitators and a process that asked them to recommend metrics that the government would measure. Their preference was to eliminate government activity altogether; therefore, the entire focus of the study did not fit within their priorities. Even so, we tried to represent their and others' concerns by suggesting environmental governance indicators around trust and representation.

The second stage of our process moved from indicator development to adoption. The research team asked the Partnership decision makers (ECB and LC) to rate the 23 indicators provided by stakeholders. To facilitate this process, relevant criteria were selected from a larger list of criteria used in the adoption of marine ecological indicators in the Puget Sound and across the United States (Kurtz et al. 2001, Kershner et al. 2011; Table 1). These criteria were approved by the Partnership SP prior to eliciting responses. The proposed indicators were sent to all members of the Partnership LC (7) and ECB (27) via an online survey in which they were asked to rate each indicator on a scale of 1 to 4 for its ability to meet the 5 criteria. Sixteen members completed the ratings. For the purpose of this analysis, indicators that received a mean response of 2.5 or higher were considered high candidates.

Additionally, as part of Partnership policy, external social scientists were requested to review the indicators and the overall process to ensure the use of the best available science. As such, we maintained a parallel scientific assessment of the locally 
Table 2. Prioritization of human well-being indicators across 3 stakeholder regions, social science (SS) reviewers, and decision makers. Indicators were marked for the regions when at least 2 workshop groups prioritized the indicator in the top 10 indicators. For the SS review, at least 2 out of 3 reviewers provided a "good" rating. For the decision makers, the indicator received a mean score of at least 2.5 , the equivalent to a score of high or very high.

\begin{tabular}{|c|c|c|c|c|c|}
\hline & $\begin{array}{c}\text { Region } 1 \\
\text { (top indicator in at } \\
\text { least } 2 \text { workshops) }\end{array}$ & $\begin{array}{c}\text { Region } 2 \\
\text { (top indicator in at } \\
\text { least } 2 \text { workshops) }\end{array}$ & $\begin{array}{c}\text { Region } 3 \\
\text { (top indicator in at } \\
\text { least } 2 \text { workshops) }\end{array}$ & $\begin{array}{l}\text { SS Review } \\
\text { (at least } 2 \\
\text { "good" } \\
\text { ratings) } \\
\end{array}$ & $\begin{array}{c}\text { Decision-Maker } \\
\text { Review } \\
\text { (mean score at least } 2.5 \\
\text { out of 4) } \\
\end{array}$ \\
\hline \multicolumn{6}{|l|}{ Physical } \\
\hline $\begin{array}{l}\text { Distance from outdoor } \\
\text { recreation }\end{array}$ & $X$ & & $\mathrm{X}$ & & $\mathrm{X}$ \\
\hline $\begin{array}{l}\text { Hours of outdoor } \\
\text { activity }^{\dagger}\end{array}$ & $\mathrm{X}$ & $\mathrm{X}$ & & & $\mathrm{X}$ \\
\hline Air quality ${ }^{\dagger}$ & $\mathrm{X}$ & $\mathrm{X}$ & $\mathrm{X}$ & $\mathrm{X}$ & $\mathrm{X}$ \\
\hline Drinking water quality & $\mathrm{X}$ & $\mathrm{X}$ & $\mathrm{X}$ & $\mathrm{X}$ & $\mathrm{X}$ \\
\hline Proximity to fresh food & $\mathrm{X}$ & & & & $\mathrm{X}$ \\
\hline $\begin{array}{l}\text { Availability of } \\
\text { commonly harvested } \\
\text { species }{ }^{\dagger}\end{array}$ & & $\mathrm{X}$ & & & $\mathrm{X}$ \\
\hline Shellfish beds ${ }^{\dagger}$ & $\mathrm{X}$ & $\mathrm{X}$ & & & $\mathrm{X}$ \\
\hline \multicolumn{6}{|l|}{ Psychological } \\
\hline $\begin{array}{l}\text { Positive connection to } \\
\text { the Puget Sound }\end{array}$ & & $\mathrm{X}$ & $\mathrm{X}$ & & $\mathrm{X}^{\dagger}$ \\
\hline Sense of stewardship ${ }^{\dagger}$ & & & $\mathrm{X}$ & & $\mathrm{X}^{\dagger}$ \\
\hline Positive feelings $^{\dagger}$ & & $\mathrm{X}$ & & & $\mathrm{X}^{\dagger}$ \\
\hline Sense of safety & $\mathrm{X}$ & & $\mathrm{X}$ & $\mathrm{X}$ & \\
\hline Subjective well-being $^{\dagger}$ & & $\mathrm{X}$ & & $\mathrm{X}$ & \\
\hline \multicolumn{6}{|l|}{ Social and cultural } \\
\hline Trust in community & $\mathrm{X}$ & $\mathrm{X}$ & & $\mathrm{X}$ & $\mathrm{X}$ \\
\hline $\begin{array}{l}\text { Community cohesion: } \\
\text { frequency of activities, } \\
\text { working with others, } \\
\text { sharing }\end{array}$ & & $\mathrm{X}$ & & $\mathrm{X}$ & \\
\hline $\begin{array}{l}\text { Participation in natural } \\
\text { resource activities }\end{array}$ & $\mathrm{X}$ & $\mathrm{X}$ & $\mathrm{X}$ & & $\mathrm{X}$ \\
\hline $\begin{array}{l}\text { Perception of cultural } \\
\text { practices }^{\dagger}\end{array}$ & $\mathrm{X}$ & & & & $X$ \\
\hline \multicolumn{6}{|l|}{ Governance } \\
\hline Trust in government ${ }^{\dagger}$ & $\mathrm{X}$ & $\mathrm{X}$ & & & $\mathrm{X}$ \\
\hline $\begin{array}{l}\text { Perception of influence } \\
\text { over natural resource } \\
\text { decisions }{ }^{\dagger}\end{array}$ & $\mathrm{X}$ & & & $\mathrm{X}$ & $\mathrm{X}$ \\
\hline $\begin{array}{l}\text { Decision-making } \\
\text { participant diversity }^{\dagger}\end{array}$ & $\mathrm{X}$ & & & & $\mathrm{X}$ \\
\hline $\begin{array}{l}\text { Engagement in } \\
\text { stewardship }^{\dagger}\end{array}$ & $\mathrm{X}$ & $\mathrm{X}$ & $\mathrm{X}$ & $\mathrm{X}$ & $\mathrm{X}^{\dagger}$ \\
\hline \multicolumn{6}{|l|}{ Economic } \\
\hline $\begin{array}{l}\text { Economic activity from } \\
\text { natural resource } \\
\text { industries }^{\dagger}\end{array}$ & $\mathrm{X}$ & $\mathrm{X}$ & & $\mathrm{X}$ & $X$ \\
\hline Living-wage jobs & & $\mathrm{X}$ & & $\mathrm{X}$ & $\mathrm{X}$ \\
\hline $\begin{array}{l}\text { Unemployment in } \\
\text { natural resource } \\
\text { industries }\end{array}$ & $\mathrm{X}$ & & & $\mathrm{X}$ & \\
\hline $\begin{array}{l}\text { Final adopted indicator } \\
\text { Placeholder for future in }\end{array}$ & $\begin{array}{l}\mathrm{r} \text { a version of). } \\
\text { cator. }\end{array}$ & & & & \\
\hline
\end{tabular}


Table 3. Criteria for final selection of indicators.

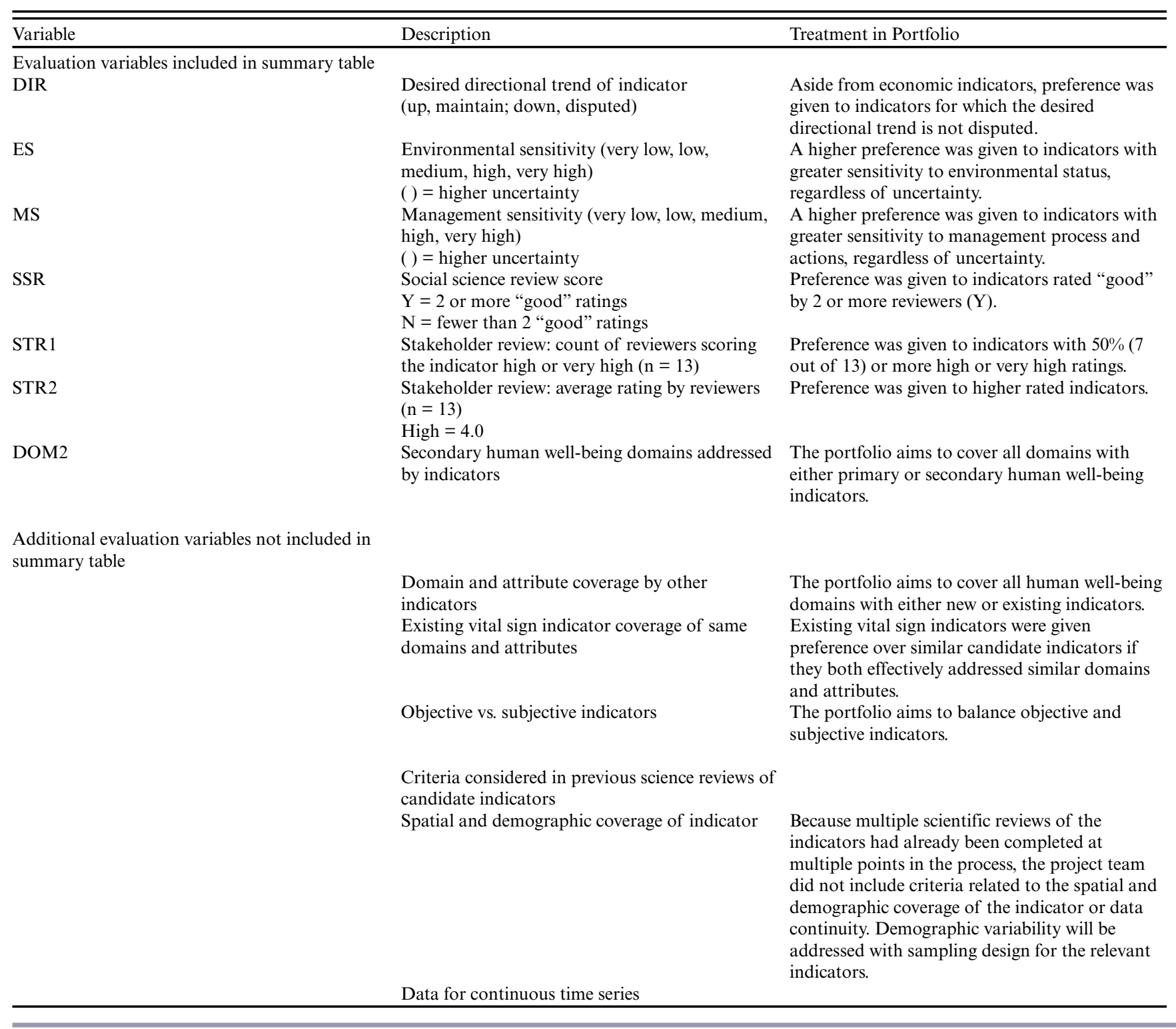

derived indicators. For the social scientists, we selected 11 criteria from the same original list (Kershner et al. 2011) that were associated with the theoretical and methodological robustness of the indicator. Again, these criteria were approved by the Partnership SP for their scientific rigor prior to eliciting responses. Three social scientists with expertise in human well-being and indicators were provided the 23 indicators in an Excel spreadsheet sent via e-mail. Respondents were asked to rate each indicator by the 11 criteria using a simple yes/no/unclear scale and then provide a final overall rating of good, provisional, or unsuitable for the indicator. Indicators that were rated "good" by at least 2 of the reviewers were considered high candidates from the social scientists.

The feedback from local stakeholders, regional decision makers, and external social scientists was critical to address the diverse concerns in the region about scientific rigor, representativeness of stakeholder values, and political feasibility. We continued this interdisciplinary prioritization into stage 3: final rankings of indicators. A task force of 2 of the authors and external social scientist and 2 other Partnership employees specializing in community outreach and coordination met to select the final indicators for adoption based on the social science and decisionmaker reviews. This team was selected because of its understanding of the science behind human well-being, the process of indicator selection, and the management context of the Partnership at regional and local scales. In an attempt to standardize the task force's decision, an additional set of criteria was developed at the recommendation of the Partnership SP after seeing the decision maker and scientific reviews and contemplating how to best defend the final selection of metrics 
Fig. 3. Average scores for the 23 indicators across the 5 criteria used by decision makers. NR, natural resource.

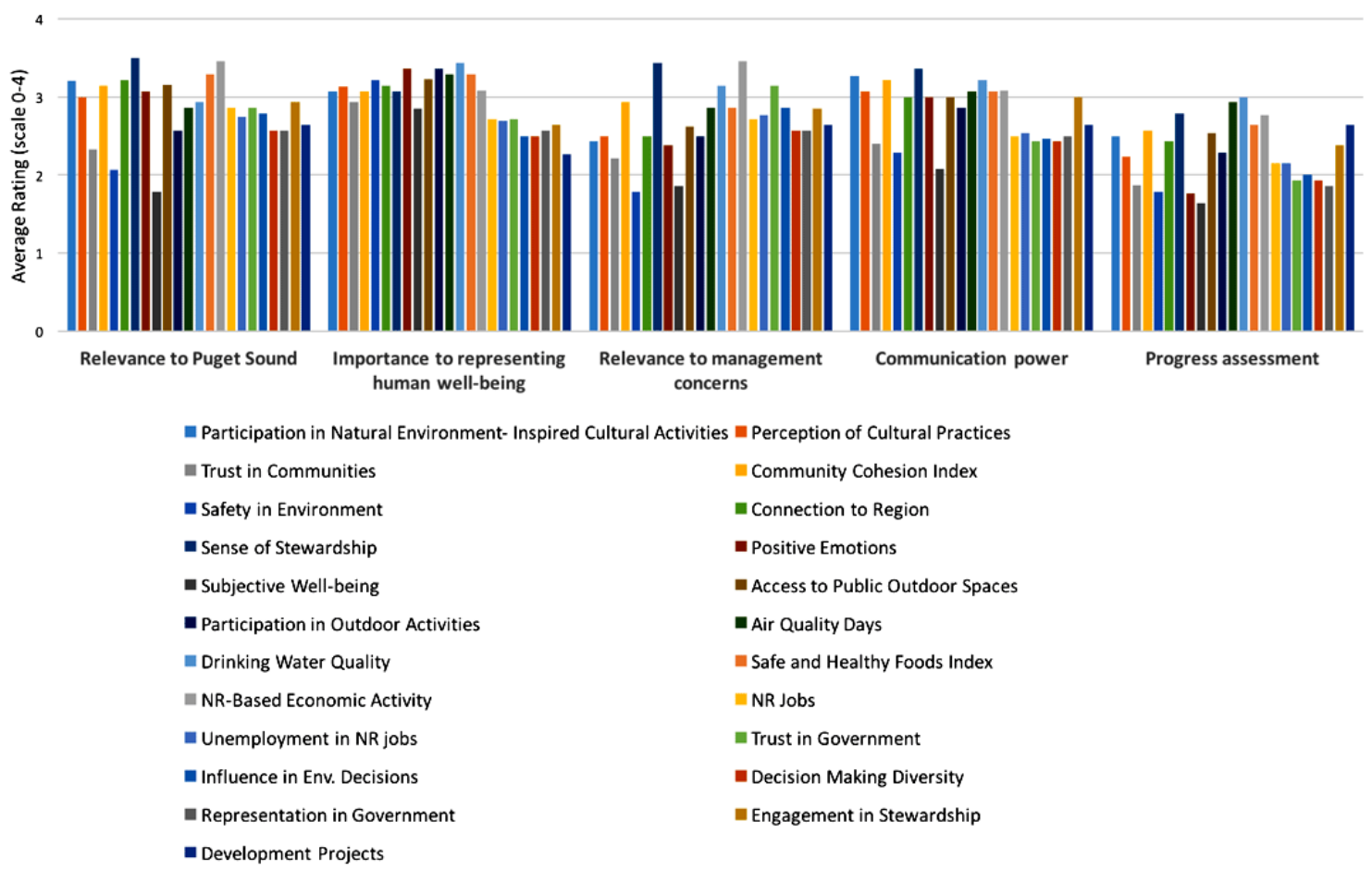

for human well-being (Table 3). These criteria included the social science and decision-maker reviews but also considered the sensitivity of the indicator to environmental and management changes, identified through expert elicitation, the desired directional trend of the indicators, the ability of the indicators to cover all previously identified domains of human well-being, i.e., economic, cultural, psychological, social, physical, and governance, and the lack of redundancy across indicators so that the final vital signs would represent all prioritized components of ecology and human health related to the Puget Sound without double counting any constructs.

\section{RESULTS}

Human well-being indicator preferences vary by user group Ten of the 23 candidate indicators were rated "good" by at least 2 of the social science reviewers (Table 2). Eight additional indicators received a combination of 1 "good" and 2 "provisional" ratings. It is worth noting that none of the indicators were rated "good" by all 3 reviewers and none of the indicators were rated "unsuitable" by more than 1 reviewer. Thus, there was no overwhelming consensus on an ideal set of well-being metrics by the social science reviewers.

Furthermore, only 1 social science reviewer completed the assessment of the 11 criteria for each indicator in addition to the overall rating. A second reviewer fully assessed the conceptual validity criteria of the indicators, i.e., theoretically sound, predictable and sensitive, and pertinent to human well-being, but not the other criteria. The third reviewer only provided an overall rating for each indicator. About an eighth of the responses to the criteria that were rated were "unclear," presumably because there is limited history of collecting such data over time, and scientists are therefore unsure of the ability to detect variation, consistently measure the construct, or ensure that the indicator responds predictably to management practices. This is supported by the fact that the social, cultural, and psychological indicators were the ones most likely to receive an unclear rating for the criteria; these categories of indicators have been tested and monitored rarely, if at all, compared to indicators for physical health, governance, and economic vitality. That said, although the individual criteria were rated as "unclear," the overall indicator rating was frequently "good" or "provisional" based on the acknowledgement that the indicator was conceptually important and worth refining with more data.

Results from the decision makers were substantially different. Eighteen of the 23 indicators had an average rating of high from this group (Table 2). Out of the 5 criteria used to assess each indicator, progress assessment was most frequently rated less than 2.5 on a 4-point scale for all indicators except sense of stewardship, air quality days, drinking water quality, safe and healthy foods, and natural resource-based economic activity and unemployment (Fig. 3). All except for unemployment received more than a 2.5 mean rating for importance to human well-being, and only 3 indicators received scores lower than 2.5 for the relevance to management concerns, communication power, and relevance to Puget Sound criteria: trust in communities, safety in the environment, and subjective well-being. The lower ratings for these 3 criteria influenced the overall low scores for those 4 indicators. Otherwise, the decision makers generally confirmed the importance of the indicators recommended by local stakeholders, although there appeared to be some trepidation at 
the ability of those indicators to assess progress toward management goals and the ability of Partnership strategies to actually affect 4 of the proposed indicators.

Summarizing the trends from all three groups, all well-being domains had representative indicators that were ranked highly, with more indicators selected and highly ranked from the physical domain (Table 2). This is likely because the indicators for the physical domain, such as drinking water quality and air quality, are more commonly used, understood, and broadly respected as objective metrics. Although we explained to the participants that both subjective and objective metrics are critical in identifying human well-being, qualitative comments throughout the process demonstrated a discomfort with subjective metrics by several stakeholders and decision makers because they were perceived as unscientific. Additionally, because of a lack of data-based evidence, social science reviewers were unsure if all the subjective indicators would vary because of ecological or management changes.

It is also interesting to note that although social science reviewers were more selective in their high ratings ( 10 out of 23 as compared to 19 out of 23 for decision makers), the only 4 that were not highly rated by decision makers were highly rated by social scientists: sense of safety, subjective well-being, community cohesion, and unemployment in natural resource-based industries. This is where the authors believe that a difference in training and understanding of social indicators and their predictability of well-being was most apparent. Within the social sciences, there is evidence that subjective well-being, feeling safe, and community cohesion are not only predictors of well-being, but sometimes the very definition of it. Decision makers, however, are less likely to see these indicators as being policy relevant. Some of this is potentially because of lack of understanding of the indicator; for instance, community cohesion is a fairly scientific term that is meant to represent a social construct that is not prevalent in our daily vocabulary. Similarly, some decision makers expressed that unemployment was not an important metric because it appeared to be the inverse of employment. Psychological research shows us, however, that losing an existing position is much more impactful on one's well-being than never having the experience to begin with.

The final adopted indicators are shown in Table 2, and Figure 4 demonstrates where these fit within the integrated ecosystem conceptual model. Figure 4 differs from the original Figure 2 in the increase in metrics that directly measure human well-being as it relates to the Puget Sound natural environment. The well-being indicator selection process moved the monitoring program from focusing on 7 metrics of human health and well-being (Fig. 2) to 11 (Fig. 4). More importantly, the original 7 metrics included only 1 direct measure of well-being that was undeveloped, and the rest proxies of how ecosystems could contribute to well-being or how human behaviors were affecting the ecosystem (Fig. 2). The newly adopted metrics placed substantially greater emphasis on a diversity of direct measures of well-being related to the natural environment (Fig. 4).

\section{DISCUSSION}

\section{The social justice of well-being indicators}

In selecting the indicators, the team developed a strategy that included diverse stakeholders and allowed them to use criteria specific to their interests. Although not the theoretical foundation for the work, nor explicitly stated as the goal of the process, the project essentially followed three aspects of pluralistic social justice: the recognition of diverse stakeholders, the participation of diverse stakeholders, and the commitment to protecting those who are least responsible and most likely to be affected by a decision (Edwards et al. 2016). In the dialogue around social justice, experts often talk about the approaches to decision making as "bottom-up," i.e., local stakeholder driven, versus "top-down," i.e., driven by those with more power, with the assumption that bottom-up approaches are more socially just because they respect the perspectives of those who will benefit from or experience harm because of a decision (Schlosberg 2007). In the development of human well-being indicators for Puget Sound, we equally weighed both bottom-up, i.e., local stakeholders, and top-down, i.e., scientists and decision makers, preferences. Our data demonstrate that had we not done so, we would have had a different set of indicators. If we had solely allowed decision makers to choose indicators, for example, we would not have had metrics of subjective well-being or unemployment in natural resource industries, metrics that were considered important by local stakeholders and scientists. If we had relied entirely on social science perspectives, we would have had very few physical and psychological metrics that currently speak to local stakeholders and regional decision makers. The fact that decision makers largely mirrored stakeholders in their assessment, however, is confounded by the fact that they were responding to stakeholder preferences rather than providing feedback on an identical set of indicators in a parallel process.

Fig. 4. Final representation of Puget Sound vital signs, including more direct metrics associated with human wellbeing. PSP, Puget Sound Partnership.

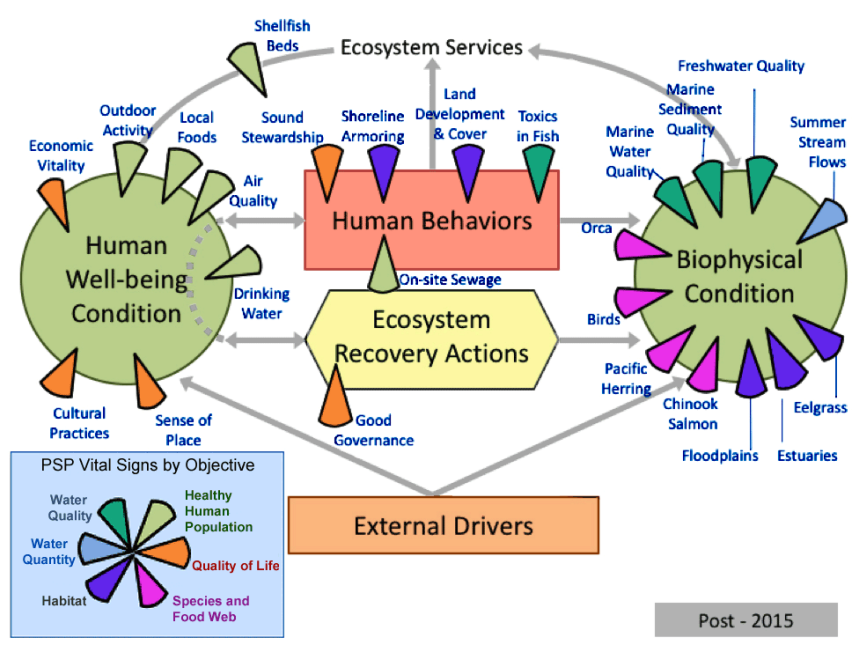

An analysis of the original and final conceptual models allows us to explore potential bias in stakeholder-driven versus decision maker-driven indicators. Although the Partnership is tasked with recovery of the Puget Sound for both human and ecological benefits, the early vital signs represented a distinct bias toward indicators of ecological health over human well-being (Fig. 2). In addition to the gaps this leaves in monitoring the social-ecological system, it had the potential to exacerbate social justice issues. The 
vital signs are used to identify restoration strategies; by developing strategies solely targeted toward ecological vital signs, such as Chinook salmon populations, there is a risk of disproportionately harming human communities because of their diverse interactions with the salmon. For example, if decision makers decided that the best strategy to increase Chinook salmon populations was to place a moratorium on Chinook fishing, Native American populations would suffer substantially more because of their social, cultural, economic, and psychological ties to the fish than populations that either have no well-being connected to the fish or are only connected to Chinook through recreational or economic benefits.

One of the first steps to enhancing social justice is to make sure all relevant stakeholders have an opportunity to participate in framing decisions. The project placed substantial effort in inviting individuals representing a wide range of values, including Native Americans, conservationists, agricultural interests, economic developers, and members of the political Tea Party movement, among others. Taking each of these local perspectives into consideration was not simply to ensure the fair distribution of benefits and consequences, but also to recognize and include the individuals in the moral and political community (Schlosberg 2007, Martin et al. 2016). A second way that social justice can be affected is through the final selection of indicators. The consideration of scientific, local, and regional preferences was an attempt at a more just process. This focus, for example, resulted in a brief negotiation to name one of the vital signs "sense of place" because it had the power to communicate to the general public, even though not all indicators of this vital sign match the academic definition of "sense of place." Finally, social justice can be influenced in how the data for indicators are collected and reported. Although the project has not completed this stage, we have outlined socially just mechanisms for doing this, including using multimodal survey tools, such as online public surveys with mail and electronic recruitment to ensure representation across age groups and in-person surveys with tribal communities, and reporting all data disaggregated by different stakeholder groups rather than overall regional means. For example, in the Puget Sound, rural residents and Native Americans are a small portion of the population with particularly tight connections to the natural environment that are substantially affected by recovery strategies. If we were to report only the average trends for wellbeing indicators across the entire population, we might inadvertently hide the fact that these groups are being negatively affected, although the rest of the human population is thriving.

Although we placed explicit effort in including all stakeholders, we still did not meet the needs of all interests. Meetings with members of the Tea Party, for example, demonstrated that although we came to understand their preferences associated with the natural environment, as soon as those preferences were translated into indicators for monitoring we digressed from their most important positions: self-reliance and no government. Similarly, there were many individuals who were not comfortable with or empowered by the opportunity to engage in workshops or interviews. We limited our project to these tools for the purposes of replication and timeliness but recognize that as a result our interests were misaligned. Finally, although we invited Native American citizens to participate in the workshops, we only had three individuals accept. Although this is demographically proportionate to the Puget Sound population, we felt it was disproportionate in terms of actual reliance on the Puget Sound to contribute to well-being. As such, we communicated with a scientist on a separate but similar project who had identified metrics of indigenous definitions of health, the majority of which were directly tied to the natural environment. The findings of the indigenous project were taken into consideration in the wording of indicators provided to the social scientists and decision makers. In sum, although it is unlikely to meet the needs of all stakeholders, there were several opportunities to explicitly attempt to do so.

\section{Competing values in policy-driven research}

The process of doing policy-driven research, not just policyrelevant research, required reconciling the competing preferences of scientists, decision makers, and the community throughout the project. For example, the research team had to juggle the needs of social science to maintain anonymity of respondents for their protection and the validity of data, whereas decision makers valued a public participation process based on transparency and trust. This played out when, for example, decision makers wanted to know the names of community members who participated in the process, ostensibly to validate the results through their personal assessment of the respondents. This was managed by reporting the organizations from which we had invited participants, but not the names of individuals. In a similar vein, there was a real need to meet regularly with the three governing bodies of the Partnership to make sure that everyone stayed informed and had the opportunity to provide feedback. This required a substantial amount of time that is not valued within the academic sector, but without it, the entire feasibility of the adoption process and ultimate use of adopted indicators to inform management decisions would have been threatened. For example, one key regional stakeholder was unfortunately not included throughout the process because of information error on the part of the research team. Once the final indicators were recommended for adoption after three years of work, this stakeholder saw the results and quickly picked up the phone to protest the process and its results. We were fortunately able to mediate the situation through dialogue.

Finally, several studies have noted that the different priorities of social science and policy result in different timelines and emphases in process (Vogel et al. 2007, Young et al. 2014). Social science processes are often slow and focused, ensuring the most rigorous study design and cautious interpretation of results, whereas the policy process is often responsive to immediate public needs, limiting the amount of time for exact specificity. This was a rare project where an academic scientist and agency staff worked together throughout the research and development process. While the scientist was carefully planning and executing data collection, the policy partners regularly led conversations focused on the long-term public funding of data collection based on the project's results. Because the project was defined by the actual political context and the topic was salient to the environmental social sciences, our results were clearly relevant to all partners.

\section{CONCLUSION}

We addressed two questions: (1) How can we integrate local, scientific, and political priorities when selecting indicators of wellbeing? (2) What does the selection of well-being indicators have 
to do with social justice? The Methods and Results provide an example for the first question based on Puget Sound restoration. For the second question, although not the explicit guiding goal, the authors felt that the Puget Sound well-being indicator selection process demonstrated a pluralistic approach to promoting environmental justice. The inclusion of scientists, decision makers, and the public in the identification and selection of indicators enabled a participatory approach in line with the capabilities framework. Specifically, diverse groups were recognized and asked to participate. Additionally, the commitment to different types of metrics, including quantitative and qualitative measures of subjective satisfaction; access to material needs such as local foods and economic benefits; and the ability to engage meaningfully in environmental governance provide the foundation to continually measure well-being in a way that is consistent with Sen's pluralistic definition of well-being. Finally, when monitoring and interpreting metrics of well-being, the Partnership staff plan to disaggregate the data for vulnerable groups, ensuring an equity-based approach to well-being reporting. Perhaps inadvertently, the Partnership well-being indicator development process provides an example for integrating well-being in environmental restoration in a socially just way. That said, although it is the Partnership's goal to protect individual rights when making management priorities, it is still unclear how compromises will be made when data demonstrate clear conflict between the preferences of different groups. The future endeavor of this team is to maintain transparency and pluralism throughout the restoration process.

Responses to this article can be read online at: http://www.ecologyandsociety.org/issues/responses. php/9424

\section{Acknowledgments:}

Funding for this research was provided by NSF grant \#1215886, the Puget Sound Institute at University of Washington Tacoma, Bonneville Environmental Foundation, the Hood Canal Coordinating Council, and the Puget Sound Partnership with EPA funding. We thank all the participants from the three regions for contributing their time in the interviews, workshops, and presentations of results. A. Hanein assisted with project design, implementation, and workshop facilitation. J. Horowitz, S. Vynne, K. Nelson, B. Le-May, J. Arnold, R. Warren, T. Webler, K. Stavros, M. Ruff, and L. Kintner facilitated workshop groups. S. Brewer, B. Peterson, M. Personious, S. Redmond, and D. Ward provided valuable feedback on recruitment and making the research process applicable to the policy process.

\section{LITERATURE CITED}

Amberson, S., K. Biedenweg, J. James, and P. Christie. 2016. "The heartbeat of our people": identifying and measuring how salmon influences Quinault tribal well-being. Society and Natural Resources 29(12):1389-1404. http://dx.doi.org/10.1080/0894192$\underline{0.2016 .1180727}$

Ban, N. C., M. Mills, J. Tam, C. C. Hicks, S. Klain, N. Stoeckl, M. C. Bottrill, J. Levine, R. L. Pressey, T. Satterfield, and K. M.
A. Chan. 2013. A social-ecological approach to conservation planning: embedding social considerations. Frontiers in Ecology and the Environment 11(4):194-202. http://dx.doi.org/10.1890/110205

Beyer, J. M., and H. M. Trice. 1982. The utilization process: a conceptual framework and synthesis of empirical findings. Administrative Science Quarterly 27:591-622. http://dx.doi. org/10.2307/2392533

Biedenweg, K. 2017. A comparative study of human wellbeing indicators across three Puget Sound regions. Society and Natural Resources 30:362-376. http://dx.doi.org/10.1080/08941920.2016.1209606

Biedenweg, K., A. Hanein, K. Nelson, K. Stiles, K. Wellman, J. Horowitz, and S. Vynne. 2014. Developing human wellbeing indicators in the Puget Sound: focusing on the watershed scale. Coastal Management 42:374-390. https://doi.org/10.1080/08920$\underline{753.2014 .923136}$

Biedenweg, K., K. Stiles, and K. Wellman. 2016. A holistic framework for identifying human wellbeing indicators for marine policy. Marine Policy 64:31-37. http://dx.doi.org/10.1016/j. marpol.2015.11.002

Cash, D. W., J. C. Borck, A. G. Patt. 2006. Countering the loadingdock approach to linking science and decision-making. Science, Technology, and Human Values 31(4):465-494. http://dx.doi. org/10.1177/0162243906287547

Cash D. W., W. C. Clark, F. Alcock, N. M. Dickson, N. Eckley, D. H. Guston, J. Jäger, and R. B. Mitchell. 2003. Knowledge systems for sustainable development. Proceedings of the National Academy of Sciences of the United States of America 100 (14):8086-8091. http://dx.doi.org/10.1073/pnas.1231332100

Collins, S. L., S. R. Carpenter, S. M. Swinton, D. E. Orenstein, D. L. Childers, T. L. Gragson, N. B. Grimm, J. M. Grove, S. L. Harlan, J. P. Kaye, A. K. Knapp, G. P. Kofinas, J. J. Magnuson, W. H. McDowell, J. M. Melack, L. A. Ogden, G. P. Robertson, M. D. Smith, and A. C. Whitmer. 2011. An integrated conceptual framework for long-term social-ecological research. Frontiers in Ecology and the Environment 9(6):351-357. http://dx.doi. org/10.1890/100068

Daily, G. 1997. Nature's services: societal dependence on natural ecosystems. Island, Washington, D.C., USA.

Diener, E., and E. Suh. 1997. Measuring quality of life: economic, social and subjective indicators. Social Indicators Research 40 (1-2):189-216. http://dx.doi.org/10.1023/A:1006859511756

Donatuto, J. L., T. A. Satterfield, and R. Gregory. 2011. Poisoning the body to nourish the soul: prioritising health risks and impacts in a Native American community. Health, Risk and Society 13 (2):103-127. https://doi.org/10.1080/13698575.2011.556186

Edwards, G. A. S., L. Reid, and C. Hunter. 2016. Environmental justice, capabilities, and the theorization of well-being. Progress in Human Geography 40:754-769. http://dx.doi.org/10.1177/030$\underline{9132515620850}$

Harguth, H., K. Stiles, K. Biedenweg, S. Redman, and S. O’Neill. 2015. Integrated conceptual model for ecosystem recovery. Puget Sound Partnership technical memorandum. Puget Sound Partnership, Tacoma, Washington, USA. 
Jenkins, L. D., S. M. Maxwell, and E. Fisher. 2012. Increasing conservation impact and policy relevance of research through embedded experiences. Conservation Biology 26(4):740-742. http://dx.doi.org/10.1111/j.1523-1739.2012.01878.x

Kahneman, D., E. Diener, and N. Schwarz. 2003. Well-being: the foundations of hedonic psychology. Russell Sage Foundation, New York, New York, USA.

Kershner, J., J. F. Samhouri, C. A. James, and P. S. Levin. 2011. Selecting indicator portfolios for marine species and food webs: a Puget Sound case study. PLoS ONE 6(10):e25248. http://dx.doi. org/10.1371/journal.pone.0025248

Kurtz, J. C., L. E. Jackson, and W. S. Fisher. 2001. Strategies for evaluating indicators based on guidelines from the Environmental Protection Agency's Office of Research and Development. Ecological Indicators 1:49-60. http://dx.doi.org/10.1016/S1470-160X (01)00004-8

Martin, A., B. Coolsaet, E. Corbera, N. M. Dawson, J. A. Fraser, I. Lehmann, and I. Rodriguez. 2016. Justice and conservation: the need to incorporate recognition. Biological Conservation 197:254-261. http://dx.doi.org/10.1016/j.biocon.2016.03.021

Millennium Ecosystem Assessment. 2005. Ecosystems and human wellbeing: synthesis. Island, Washington, D.C., USA.

National Research Council. 2000. Ecological indicators for the nation. National Academy, Washington, D.C., USA.

Norton, B. G. 2015. Sustainable values, sustainable change: a guide to environmental decision making. University of Chicago Press, Chicago, Illinois, USA. http://dx.doi.org/10.7208/

chicago/9780226197593.001.0001

Ostrom, E. 2009. A general framework for analyzing sustainability of social-ecological systems. Science 325:419-421. http://dx.doi.org/10.1126/science. 1172133

Pelz, D. C. 1978. Some expanded perspectives on use of social science in public policy. Pages 346-357 in M. Yinger and S. J. Cutler, editors. Major social issues: a multidisciplinary view. Free, New York, New York, USA.

Puget Sound Institute. 2015. Puget Sound Fact Book. Version 3.0. University of Washington Tacoma, Tacoma, Washington, USA. [online] URL: http://www.eopugetsound.org/sites/default/files/ features/resources/PugetSoundFactbook_v3.0.pdf

Puget Sound Partnership. 2014. The 2014/2015 action agenda for Puget Sound. Puget Sound Partnership, Tacoma, Washington, USA.

Rose, D. C. 2015. The case for policy-relevant conservation science. Conservation Biology 29(3):748-754. http://dx.doi. org/10.1111/cobi.12444

Rudd, M. A. 2011. How research-prioritziation exercises affect conservation policy. Conservation Biology 25:860-866. http://dx. doi.org/10.1111/j.1523-1739.2011.01712.x

Samhouri, J. F., P. S. Levin, and C. J. Harvey. 2009. Quantitative evaluation of marine ecosystem indicator performance using food web models. Ecosystems 12:1283-1298. http://dx.doi.org/10.1007/ $\underline{\text { s10021-009-9286-9 }}$
Satterfield, T., R. Gregory, S. Klain, M. Roberts, and K. M. Chan. 2013. Culture, intangibles and metrics in environmental management. Journal of Environmental Management 117:103-114. http://dx.doi.org/10.1016/j.jenvman.2012.11.033

Schlosberg, D. 2007. Defining environmental justice: theories, movements, and nature. Oxford University Press, New York, New York, USA. http://dx.doi.org/10.1093/acprof:oso/978019928629$\underline{4.001 .0001}$

Schlosberg, D. 2013. Theorising environmental justice: the expanding sphere of a discourse. Environmental Politics 22 (1):37-55. http://dx.doi.org/10.1080/09644016.2013.755387

Scott, K. 2012. Measuring wellbeing: towards sustainability? Routledge, London, UK.

Sen, A. 1999. Development as freedom. Oxford University Press, Oxford, UK.

Sullivan, P. J., J. M. Acheson, P. L. Angermeier, T. Faast, J. Flemma, C. M. Jones, E. E. Knudsen, T. J. Minello, D. H. Secor, R. Wunderlich, and B. A. Zanetell. 2006. Defining and implementing best available science for fisheries and environmental science, policy and management. Fisheries 31 (9):460-465.

Sutherland, W. J., E. Fleishman, M. B. Mascia, J. Pretty, and M. A. Rudd. 2011. Methods for collaboratively identifying research priorities and emerging issues in science and policy. Methods in Ecology and Evolution 2:238-247. http://dx.doi.org/10.1111/ j.2041-210X.2010.00083.X

Vogel C., S. C. Moser, R. E. Kasperson, G. D. Dabelko. 2007. Linking vulnerability, adaptation, and resilience science to practice: pathways, players, and partnerships. Global Environmental Change 17:349-364. http://dx.doi.org/10.1016/j. gloenvcha.2007.05.002

Wellman, K. F., K. Biedenweg, and K. Wolf. 2014. Social sciences in Puget Sound recovery. Coastal Management 42:298-307. https://doi.org/10.1080/08920753.2014.923129

White, S. C. 2010. Analysing wellbeing: a framework for development practice. Development in Practice 20(2):158-172. http://dx.doi.org/10.1080/09614520903564199

Yee, S. H., P. Bradley, W. S. Fisher, S. D. Perreault, J. Quackenboss, E. D. Johnson, J. Bousquin, and P. A. Murphy. 2012. Integrating human health and environmental health into the DPSIR framework: a tool to identify research opportunities for sustainable and healthy communities. EcoHealth 9:411-426. http://dx.doi.org/10.1007/s10393-012-0805-3

Young, J. C., K. A. Waylen, S. Sarkki, S. Albon, I. Bainbridge, E. Balian, J. Davidson, D. Edwards, R. Fairley, C. Margerison, D. McCracken, R. Owen, C. P. Quine, C. Stewart-Roper, D. Thompson, R. Tinch, S. Van den Hove, and A. Watt. 2014. Improving the science-policy dialogue to meet the challenges of biodiversity conservation: having conversations rather than talking at one-another. Biodiversity and Conservation 23:387-404. http://dx.doi.org/10.1007/s10531-013-0607-0 